\title{
An Ecological Assessment of the Physico-chemical and Biological Water Quality in a Sub-urban Area in Cameroon: Case of the Ngoumou Rural Council
}

\author{
Ngakomo Ananga Rose Pulcherie ${ }^{1, *}$, Ajeagah Gideon Aghaindum ${ }^{1}$, Zeinab Abou Elnaga ${ }^{2}$, \\ Ngassam Pierre ${ }^{1}$ \\ ${ }^{1}$ Laboratory of Hydrobiology and Environment, Faculty of Science, University of Yaounde 1, Yaounde, Cameroon \\ ${ }^{2}$ Laboratory of Zoology, Faculty of Science, University of Mansoura, Mansoura, Egypt

\section{Email address:} \\ otonia2001@yahoo.fr (N. A. R. Pulcherie), Ajeagahg@yahoo.com (A. G. Aghaindum), dr.z.aboelnaga@gmail.com (Z. A. Elnaga), \\ mbeungassam@yahoo.fr (N. Pierre) \\ ${ }^{*}$ Corresponding author
}

\section{To cite this article:}

Ngakomo Ananga Rose Pulcherie, Ajeagah Gideon Aghaindum, Zeinab Abou Elnaga, Ngassam Pierre. An Ecological Assessment of the Physico-chemical and Biological Water Quality in a Sub-urban Area in Cameroon: Case of the Ngoumou Rural Council.International Journal of Natural Resource Ecology and Management. Vol. 4, No. 6, 2019, pp. 198-204. doi: 10.11648/j.ijnrem.20190406.16

Received: October 29, 2019; Accepted: November 23, 2019; Published: December 6, 2019

\begin{abstract}
In developing countries, most of the population does not have access to drinking water and is therefore subject to use groundwater and surface water for it's domestic needs without taking into consideration it's quality and health repercussions. This study seeks to assess the physicochemical and biological quality of water in some springs, wells and streams of the Ngoumou municipality in Cameroon. Several physico-chemical parameters coupled to biological variables were applied in the evaluation of the quality of these waters. The physicochemical quality was evaluated by standard methods for the monitoring of water quality. Biological analyses were performed by the direct method and the Zhiel-Neelsen method using a $40 \mathrm{X}$ and $100 \mathrm{X}$ optical microscope. The physico-chemical analysis reveals a low organic pollution and shows that these waters are acidic, lowly mineralized and presents low oxygen saturation. The biological quality revealed the presence the oocystic load of Cryptosporidium sp (872 oocysts/L), Cyclospora sp $(224$ oocysts/L) and Isospora sp (133 oocysts/L). Oocysts of Cryptosporidium sp (170oocysts/L) were identified in the aquatic system of the Ngoumou sub-urban area. Oocysts density was positively correlated with suspended solids, water color and turbidity. The presence of these organisms in this communal water system depicts faecal contamination. It is urgent to raise awareness on the protection of this precious natural resource and safe the population from rampant diarrheal diseases.
\end{abstract}

Keywords: Water Quality, Wells Springs, Streams, Oocysts, Pollution

\section{Introduction}

Pollution and water scarcity are in fact a global problem whose aspect and scopes are different, according to the levels of development of the nations. In Cameroon, despitethe presence of water in quantity, it remains a limited resource, vulnerable, indispensable to the environment and essential to life [1]. The production of clean and safe drinking water still remains a major problem in our society [2]. The peri-urban and rural areas are a perfect illustration of this because, due to budget constraints, public investments are becoming increasingly insufficient to meet the water needs of an increasingly growing population. The absence of the public water supply network obliges the villagers to obtain supplies directly from surface and underground water. This is the case in the district of Ngoumou where people rely on springs, well and streams for their domestic needs [3]. Those who are at risks of diseases (amoebic dysentery, giardiasis, abdominal pain and diarrhea) carried by this water are infants, young children, and immunocompromised people. Indeed almost $60 \%$ of infant mortality worldwide is attributable to water-related infectious diseases [4].

Indeed, some studies on groundwater and surface water in Cameroon, in area urban and peri-urban have shown that these 
water host germs which are fecal indicators of contamination. The oocysts of Cryptosporidium sp, Cyclospora sp, Isospora $\mathrm{sp}$ are cosmopolitan and can withstand various environmental stresses. It would therefore be necessary to evaluate the quality of the surface and depth of water consumed by the population through some physico-chemical variables and some biological indicators of the quality of water used in peri-urban areas.

\section{Materials and Methods}

\subsection{Study Site}

This study was conducted over a 13 months period from March 2017 to May 2018. The districts of Ngoumou which extends between $3^{\circ} 35^{\prime} 0^{\prime \prime}$ and $3^{\circ} 35^{\prime} 30^{\prime \prime}$ ofNorthern latitude and between $11^{\circ} 17^{\prime} 30^{\prime \prime}$ to $11^{\circ} 18^{\prime} 30^{\prime \prime}$ of Eastern longitude. This district is found in the division of Mefou-and-Akonowhich is located in the Central region, South of Yaounde, the capital of Cameroon.

\subsection{Presentation of Sampling Stations}

The choice of sampling stations was made according to the criteria such as: the sources of contamination, the use of water, the importance of thewater point for the populations, the lack of adequate sanitation, the precarious hygienic situation and the accessibility of these areas [5,6]. A total of 06 stations where chosen in the district of Ngoumou such as 02 wells (NP1 and NP2), 02 springs (NS1 and NS2) and 02 points on the Ebongo stream. That flows across the whole locality.

The Ebongo stream in the Ngoumou locality is subject to some anthropogenic pressures suchdumping garbage, toilets released into the stream, and water pollution. This river is used by local residents for bathing, washing of automobiles and as a watering point for cattle that serve as meat in the area. The NP2 well which is located at Ngoumou is about 6 meters from the toilet; this well is an unprotected well without lip or cover simply dug in the ground, whose edges are covered with a plank. The Ngoumou NP1 well is nicely protected by a crops and a cover. The sources NS1and NS2 are unprotected.

\subsubsection{Physicochemical Parameters}

The physicochemical analyses were carried out both on the field and in the laboratory of Hydrobiology and Environment of the University of Younde I, following the recommendations of Rodieret al [7]. For laboratory analyzes, water sampleswere collected in the field using 250 and $1000 \mathrm{ml}$ double sided polyethylene vials. The physicochemical analyzes were carried out by volumetric process, colorimetry with spectrophotometer HACH DR 2100 and with the aid of a portable multiparameter HANNA model HI 9829. Physicochemical parameters were temperature, Suspended Solids (SS), Colour, Turbidity, Nitrate, Orthophosphates, Hydrogen Potential $(\mathrm{pH})$, Electrical Conductivity, Total Dissolved Solids (TDS), Dissolved Oxygen (D O), Dissolved Carbon Dioxide $\left(\mathrm{CO}_{2}\right)$ and Oxydability.

\subsubsection{Biological Variables}

For the biological analysis, $1 \mathrm{~L}$ of water sample is taken to the laboratory and left for sedimentation during 24 hours at room temperature. The deposits obtained are then quantified, homogenized and a sub sample of $10 \mathrm{ml}$ per sample was taken and distributed into the tubes to which $0.5 \mathrm{ml}$ of formalin was added. Two identification methods were used to isolate and to enumerate the oocysts. This is the direct observation method and the Ziehl-Neelsen technique. The direct observation method consist of adding $5 \mathrm{~mL}$ of distilled water and a few drops of dye (Lugol, MIF, basic fuschine, hématoxyline or methylene blue), which stain the internal structures of sporocysts [8]. And the contents of the tubes are centrifuged at $500 \mathrm{rpm}$ for five minutes. The pellets are taken using a micropipette and placed on slides; the examination and enumeration of the oocysts are performed under the Olympus CK2 microscope at a 40X magnification.

The Zielh-Neelsen technique consists of adding a solution of zinc sulphate $(10 \%)$ to the $10 \mathrm{ml}$ pellet, which is then centrifuged at $500 \mathrm{rpm}$ for five minutes to float the oocysts. The supernatant, containing the oocysts is removed using a micropipette and placed on microscope slides which are then dried, after fixation with methanol and stained with basic fuchsine; the preparation is rinsed with water and then sulfuric acid (2\%). Counterstaining is effected with methylene blue $(5 \%)$. After rinsing with water and drying in the air, the examination and enumeration of the oocysts are carried out under Olympus CK2microscope40X magnification.

\subsubsection{Analysis of the Results and Statistical Test}

The integral volume "(2)", of the pellet is recorded. After homogenization of the pellet, a precise volume "(3)", is taken and introduced into atest tube. The final pellet of each oocyst in the sampleis calculated, the rest in the tube is distributed on slides, then the number of oocystesis counted by multiplying the value obtainedon all the slides by the fraction "(4)", and the result is finallycalculated to a liter and the number of oocystis noted per liter (oocyst /L) [9]. The collected data weregrouped by season using the Microsoft Excell program 2010 and processed is using SPSS version 20.0 software as the data. The distribution does not follow a normal distribution, the dependence relationships between physic-chemical and biological parameters wereevaluated by the " $\mathrm{r}$ " correlationtest of Spearman. These analyses were performed using the SPSS 20.0 software and the results are evaluated at the safety thresholds of $1 \%$ and $5 \%$.

$$
\mathrm{X}=\mathrm{Y} \cdot \mathrm{V}_{\mathrm{x}} / \mathrm{V}_{\mathrm{y}}
$$

AndX it is a number oocyst finally per liter (oocyst/L)

$\mathrm{Y}$ a value obtained on all the slides

$\mathrm{Vx}$ anintegral volume of the pellet is recorded (2)

Vy a precise volume is taken and introduced into a test tube (3) $\mathrm{Vx} / \mathrm{Vy}$ the fraction (4) 


\section{Results}

\subsection{Physicochemical Results}

In the locality of Ngoumou, the temperature of the groundwater (NS1, NS2, NP1 and NP2) varies from 23 to $27^{\circ} \mathrm{C}$, with an average of $25.3 \pm 1.2^{\circ} \mathrm{C}$. This groundwater is low in turbidity which varies from 1 to $35 \mathrm{FTU}$, with an average of $9.9 \pm 10.2$ FTU. The color values are between 3 and $197 \mathrm{Pt}-\mathrm{Co}$, with an average of $35.45 \pm 45.7 \mathrm{Pt}-\mathrm{Co}$. The contents of Suspended Solid (SS) are between 1 and $15 \mathrm{mg} / \mathrm{L}$, with an average of $6.8 \pm 4,8 \mathrm{mg} / \mathrm{L}$. The groundwater $\mathrm{pH}$ in NS1, NS2, NP1 and NP2 varies from 5 to $7.2 \mathrm{UC}$, with an average of $5.99 \pm 0.55 \mathrm{UC}$. The electrical conductivity is low and between 43.0 and $172.0 \mu \mathrm{S} / \mathrm{Cm}$, with an average of $98.2 \pm 45.39 \mu \mathrm{S} / \mathrm{Cm}$. Total dissolved solids range from 19 to $86 \mathrm{mg} / \mathrm{L}$, with an average of $44.4 \pm 21.4 \mathrm{mg} / \mathrm{L}$. Groundwater concentrations in dissolved oxygen are very low, ranging from $0.3(3.57 \%)$ and $1.6 \mathrm{mg} / \mathrm{L}(20.09 \%)$ with an average of $0.86 \mathrm{mg} / \mathrm{L}(10.50 \%)$. Carbone Dioxide (CO2) has values between 12.32 and 42.24 $\mathrm{mg} / \mathrm{L}$, with an average of $20.1 \pm 7.9 \mathrm{mg} / \mathrm{L}$. The organic matter content is low; the concentration is between 0.9 to $2 \mathrm{mg} / \mathrm{L}$, with an average of $1.6 \pm 0.2 \mathrm{mg} / \mathrm{L}$. The nitrate concentration is between 0.2 and $6.2 \mathrm{mg} / \mathrm{L}$, with an average of $2.25 \pm 1.4 \mathrm{mg} / \mathrm{L}$. The orthophosphates concentrations range from 0 to $4.3 \mathrm{mg} / \mathrm{L}$, with an average of $2.1 \pm 1.01 \mathrm{mg} / \mathrm{L}$. nitrates and orthophosphates concentrations are low compared to WHO standards for drinking water [10].

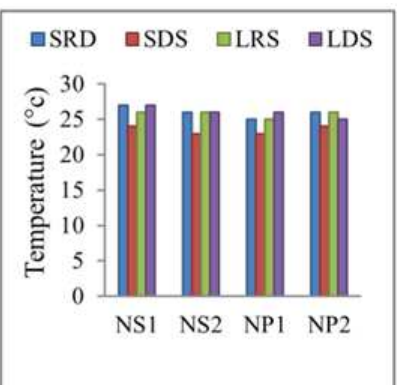

(a)

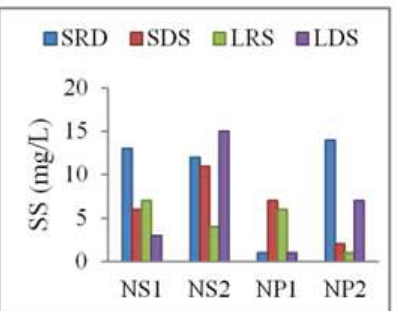

(c)

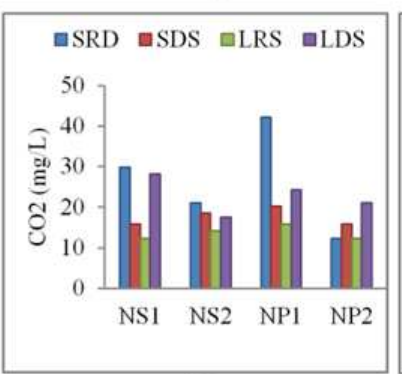

(e)

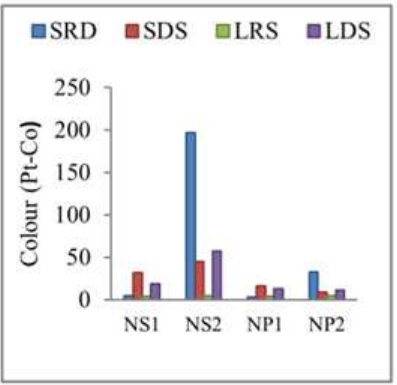

(b)



(d)



(f)

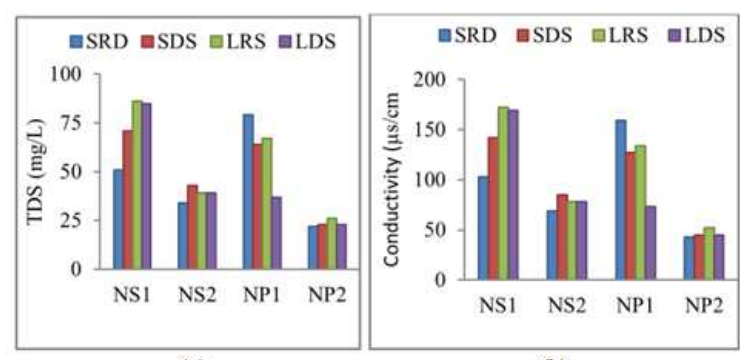

(g)

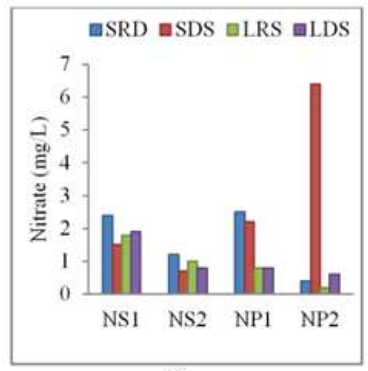

(i)

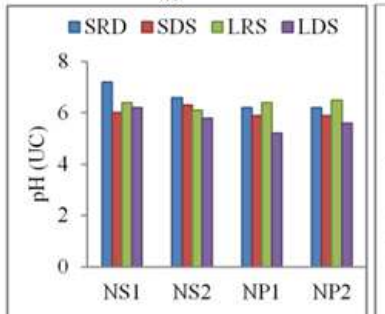

(k) (h)


(1)

Figure 1. Spatiotemporal variation of the physicochemical variable obtained during the whole study period in the Groundwater of Ngoumou Municipality: (Temperature (a), Colour (b), SS (c), DO (d), $\mathrm{CO}_{2}(e)$, Oxydability (f), TDS (g), Electrical conductivity (h), Nitrates (i), Turbidity (j), pH (k) and Orthophosphates (l)).

In Ebongo river the temperature of the water varies slowly. This stream has almost similar diagrams (figure 2). It evolves between 21 and $24^{\circ} \mathrm{C}$ with amplitude of $3^{\circ} \mathrm{C}$ and respective average of $23.5 \pm 1.08^{\circ} \mathrm{C}$. The turbidity of the water varies from 6 to 57 FTU in the Ebongo stream. Surveys of SS show different variations and oscillate between 6 and $57 \mathrm{mg} / \mathrm{L}$. The water of this river show a high colour with values ranging from 97 to 312 Pt.Co for the stream assessed.

In the Ebongo river, the $\mathrm{pH}$ fluctuates between 5.1 and 6.9 $\mathrm{CU}$ with an average of $6.2 \pm 0.2 \mathrm{CU}$. Conductivity remained low in this stream. In the Ebongo stream, it ranges from 31 to $56 \mu \mathrm{S} / \mathrm{Cm}$ with an average of $38 \pm 9 \mu \mathrm{S} / \mathrm{cm}$ and the TDS range from 13 and $28 \mathrm{mg} / \mathrm{L}$ with an average of $19 \pm 4 \mathrm{mg} / \mathrm{L}$. Similarly an oxygenation percentage is very low and ranges between 3.56 and $27.32 \%$ with an average of $11.7 \pm 7.7 \%$. In Ebongo river, the organic matter load is between 1.8 and $3.1 \mathrm{mg} / \mathrm{L}$ with an average of $2.3 \pm 0.4 \mathrm{mg} / \mathrm{L}$. The highest seasonal value is noted during the LDS and the lowest during the SRS. The orthophosphates content varies from 0 to $2.4 \mathrm{mg} / \mathrm{L}$ and the nitrates values are between 0.1 and $3 \mathrm{mg} / \mathrm{L}$.

The oocysts of Isospora sp observed have an oval shape, refracting, with a double wall and measure from 20 to $30 \mu \mathrm{m}$ of length on 12 to $16 \mu \mathrm{m}$ wide. They contain a sporoblast and sometimes a more or less differentiated two sporocysts (figure 4). 




(a)

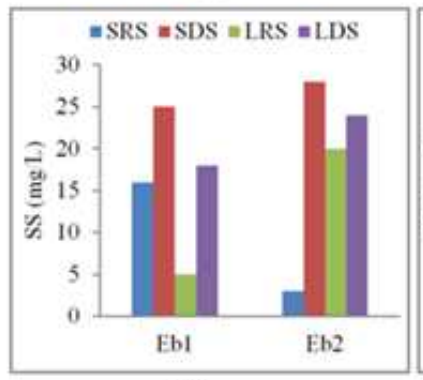

(c)

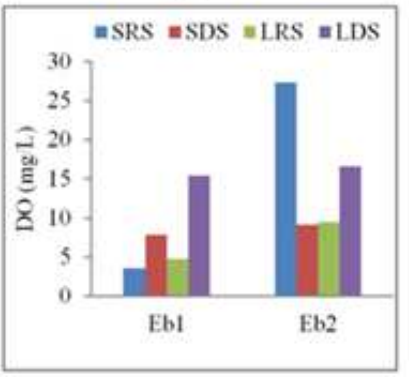

(d)

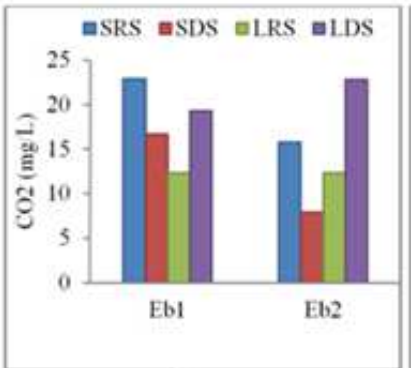

(e)



(g)

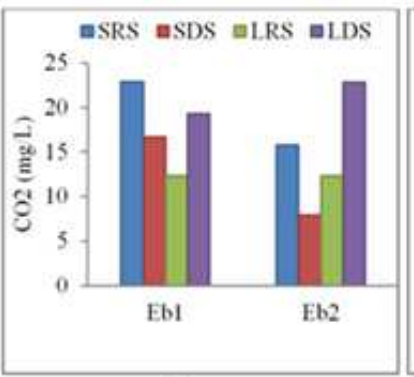

(e)

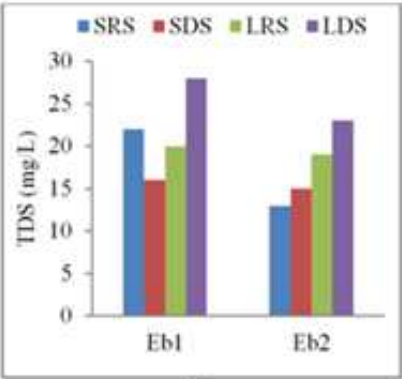

(g)

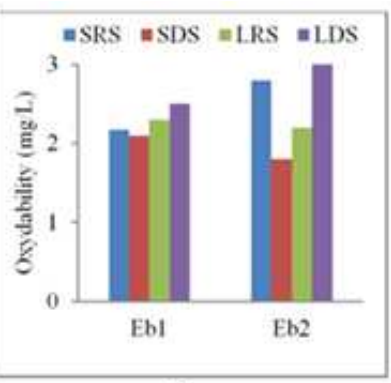

(f)

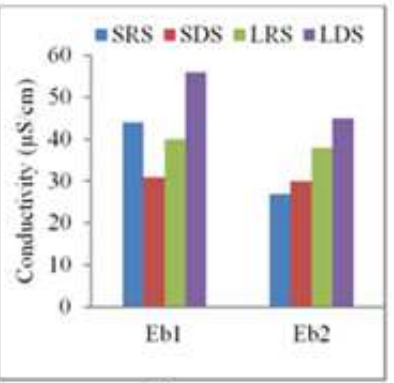

(h)

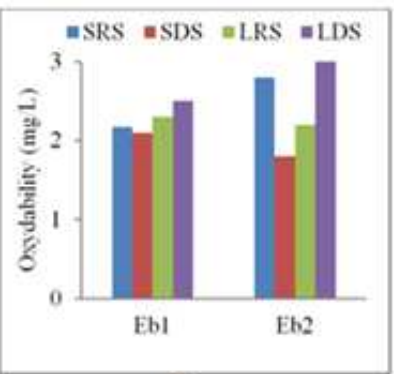

(f)



(h)

Figure 2. Spatiotemporal variation of the physicochemical variable obtained during the whole study period in the water course (Ebongo river) of Ngoumou Municipality: (Temperature (a), Colour (b), SS (c), DO (d), $\mathrm{CO}_{2}(\mathrm{e})$, Oxydability (f), TDS (g), Electrical conductivity (h), Nitrates (i), Turbidity (j), pH (k) and Orthophosphates (l)).

\subsection{Biological Results}

In total, three types of intestinal coccidian have been identified, namely Crytosporidium sp; Cyclospora sp and Isospora sp. The oocysts of Cyclospora sp observed are sporulated and non-sporulated forms, have a diameter between 8 and $10 \mu \mathrm{m}$ and are spherical in shape with an outer fibrillarylayer $(63 \mathrm{~nm})$ whichcovers a thick cell wall $(50 \mathrm{~nm})$. The non-sporulated forms occur with clusters of $2 \mu \mathrm{ms}$ refractive globules and the sporulated oocysts have two sporocysts each containing two sporozoits (figure 3).

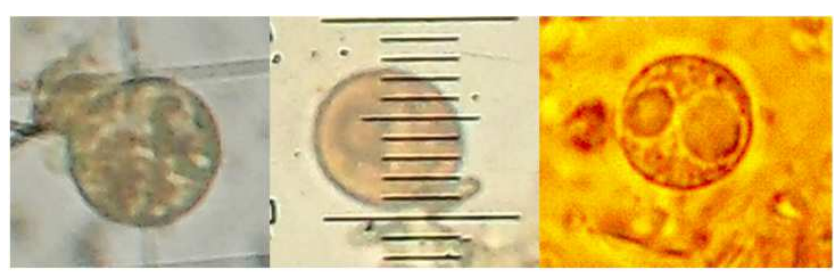

(a)

(b)

(c)

Figure 3. Oocysts of cyclospora sp see under a 40X optical microscope: (A) non sporulated oocysts ( $B$ and $C$ ) oocysts sporulated. 
Figure 5 shows the oocysts of Cryptosporidium sp observed have a spherical shape. Their diameter varies between 4 and 6 $\mu \mathrm{m}$ depending on the species. Their wall is thick and composed of two layers, internal and external, quite distinct. Their contents are granular.

The results of the microbiological analyses presented on figure 6 shows that the density of oocysts in groundwater ranges from 0 and 55 oocystes/L for all genera identified, with an average density of 66 oocystes/L for Cryptosporidium sp, 24 oocysts/L for Cyclospora sp and 26 oocysts/L for Isopora sp. The oocysts of Cryptosporidium sp, were the most abundant in the wells and springs assessed.

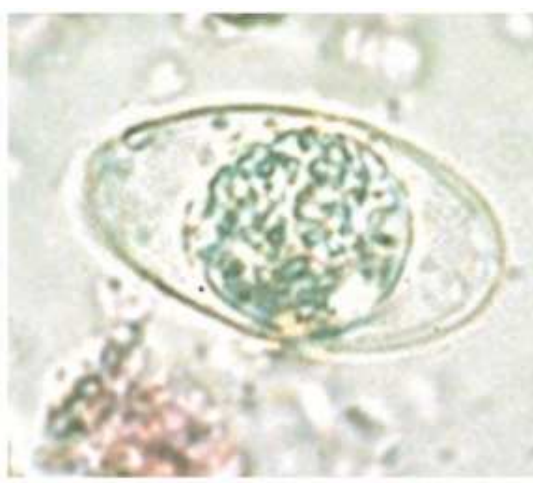

(a)

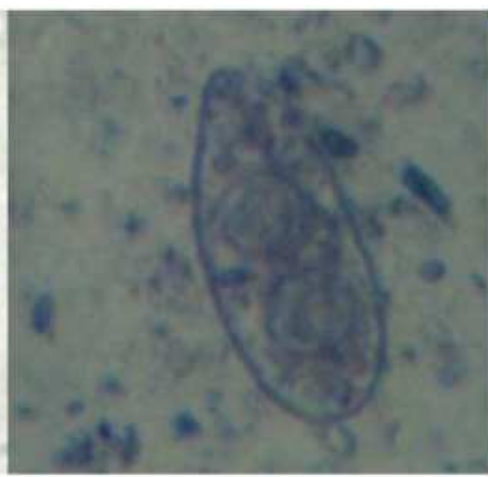

(b)



(c)

Figure 4. Oocysts of Isospora sp see under a 40X microscope: (a) non sporulated oocysts, (b and c) oocysts sporulated.

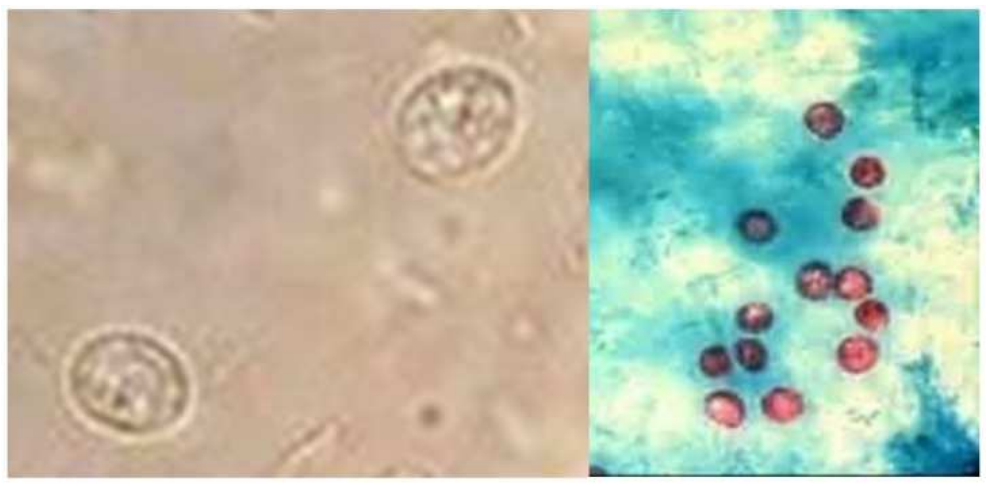

(a)

(b)

Figure 5. Oocysts of Cryptosporidium sp see under a microscope.



Figure 6. Spatiotemporal Variations of oocysts identified in groundwater



Figure 7. Variation of abundance the distribution of coccidian densities identified in groundwater. 


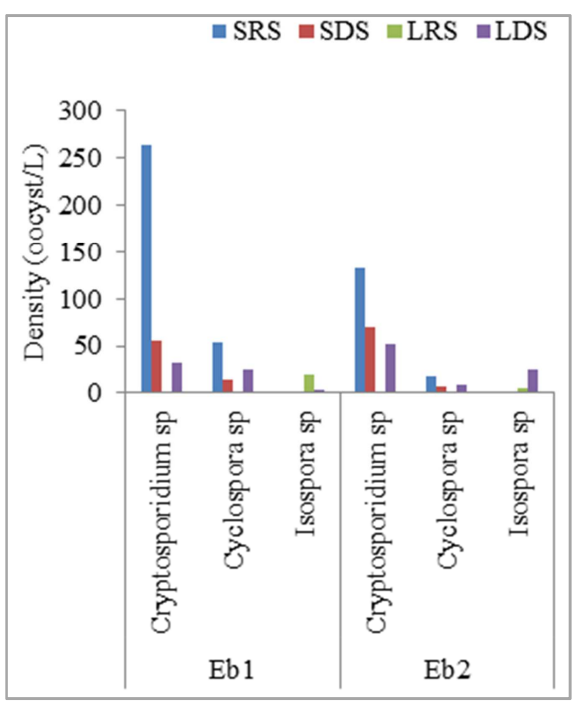

Figure 8. Spatiotemporal Variations of oocysts identified in Ebongo river.

These organisms are present in all seasons, Ns2 source is the most pest-laden source in all seasons and are more abundant during LDS.

In Ebongo river the density of oocysts ranges from 0 and 266 oocysts/L and the Cryptosporidium sp oocysts were most abundant with an average density of 303 oocystes/L followed by those of Cyclospora sp which have an average density of 62 oocysts/L. The highest density of coccidia was obtained in the Eb1 station during the SRS.

It is noted that the density of the identified sporocyts evolves in the opposite direction with the level of mineralization as indicated by the correlation values between the conductivity, the TDS and the density of Cryptosporidium $\mathrm{sp}$, Cyclospora sp and Isospora sp. These correlation are significant $(\mathrm{p}>0.01)$ with the density of oocysts of Cryptosporidium sp $(\mathrm{r}=-0,371 ; \mathrm{p}=0.000)$. SS, Color and Turbidity values are in the same direction, as the density of the Cryptosporidium sp. oocysts of Cyclospora $\mathrm{sp}$, Isospora $\mathrm{sp}$ and Cryptosporidium sp remain significantly correlated significantly at the $1 \%$ threshold with these three parameters. Whereas Cyclospora sp shows a significant correlation at the $5 \%$ threshold as shown in table 1 .

$\because \mathrm{SRS} \backsim \mathrm{SDS} \backsim \mathrm{LRS} \backsim \mathrm{LDS}$

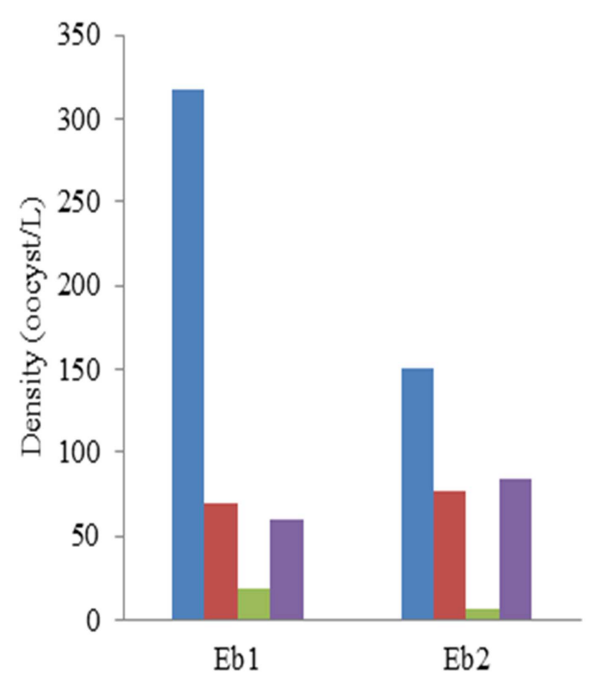

Figure 9. Variation of abundance the distribution of coccidian densities identified in Ebongo river.

Table 1. Correlation obtained between the physicochemical parameters and densities of Cryptosporidium, Cyclospora and Isospora oocysts.

\begin{tabular}{lllll}
\hline & Conductivity $(\boldsymbol{\mu S} / \mathbf{c m})$ & TDS $(\mathbf{m g} / \mathbf{L})$ & SS $(\mathbf{m g} / \mathbf{L})$ & Colour Pt/Co \\
\hline Cryptosporidium sp & $-0,371^{* *}$ & $-0,354^{* *}$ & $0,436^{* *}$ & $0,480^{* *}$ \\
Cyclospora sp & $-0,32$ & $-0,008$ & $0,285^{*}$ & 0,198 \\
Isospora sp & $-0,90$ & $-0,062$ & 0,129 & 0,120 \\
\hline
\end{tabular}

$*$ = significant correlation at the threshold $5 \%$ and $* *=$ significant correlation at the threshold $1 \%$.

\section{Discussion}

Water temperature is an important factor in the aquatic environment because it regulates almost all physical, chemical and biological metabolic activities [11]. In the present study the temperature didn't show any significant variation from one well, spring or surface waters sampling points. These temperatures are favorable for the proliferation of enteropathogenic protozoan species identified in our samples. The case of Cryptosporidiumsp oocyststhat can remain viable and infectious in water at temperatures up to $30^{\circ} \mathrm{C}$ [12], similarly for Cyclosporasp whose sporulation dependent on the temperature which must be between $22^{\circ} \mathrm{C}$ and $32^{\circ} \mathrm{C}[12$, 13]. Human contamination is most often related to consumption of untreated wateror ingestion of contaminated food. After ingestion by the humans, oocysts lose their protective shell in the gastrointestinal tract and releasesporozoïts, which invade the epithelial cells of the small intestine and cause diarrhea, abdominal cramps or bloating and nausea [14].

The $\mathrm{pH}$ of the water provides information on its acidity and alkalinity [15]. The results revealed that the waters of the locality of Ngoumou are acidic, the average $\mathrm{pH}$ of the waters is 5.9 UC for the groundwaters and 6.3 UC for surfaces water and these values are explained by the nature of soils that are clayey nature and ferralitic. The Ngoumousurface water is weakly mineralized. In our samples, the conductivity was between 37 and $218 \mu \mathrm{S} / \mathrm{cm}$ for the groundwater and between 26 and $56 \mu \mathrm{S} / \mathrm{cm}$ for surface water. This difference can be explained by the period of duration of water in the geological formation which is greater and water has more time to be loaded with minerals, than the water of river. Dissolved oxygen levels in groundwater have been relatively low, compared to surface water, which is the seat of the photosynthetic activity and permanent mixing. Turbidity, color and SS values are generally low; this shows a moderate enrichment in organic matter of these waters. These particles 
may be a signification of pollution and it also a channel for the transmission of microorganisms.

In the groundwater of this locality we obtain an average density of 145 oocystes/L whereas in surface water we observe an average density of 398 oocystes/L. This difference in density can be explain by the fact that the groundwater undergoes a filtration process in soil which limits the contamination of the aquifer by surface water contracted with most often places of receptacle of all kinds anthropogenic waste. The presence of microorganisms in wells and protected springs could be explained by the shallowness of the majority of the two wells, we also noted problems such as non-sealing and poor maintenance which is also a factor of contamination. The risks of contamination are increased in shallow wells because the water is filtered to alower level [16]. Temporally, the abundance of oocysts of Cryptosporidium could be explained by the fact that Cryptospridiumoocysts have a thick double membrane, which are resistant to many chemicals; these oocysts can survive to higher temperature such as $30^{\circ} \mathrm{C}$ and moist environments for up to six months. Increase turbidity in the water may indicate microbiological problems. In the environment microorganisms became intimately associated with soil and waste particles. Several studies have established correlation between increased concentrations of microorganisms and increased turbidity [17, 12, 13]. The quality of water and food are therefore a priority.

\section{Conclusion}

The eco-assessment of springs, wells and streams in theperi-urban area of Yaounde show alow organic pollution and a low mineralization. Water quality is acceptable at the level of physicochemical analysis. Regarding the biological aspect, groundwater contains fewer oocysts than surface water. Cryptospridiumoocysts were the most abundant followed by Cyclospora oocysts. The density of these environmental forms has evolved in the same direction as the level of Suspended Solids, color and turbidity. Regarding the biological quality, the presence of oocysts translates fecal contamination of the ecosystem assessed. Although of good physicochemical quality, the presence of the resistance forms of pathogens such as Cryptosporidium spand Cyclospora sp enables us to predict in favor of an in-depth study on protozoa and their role in the bio-evaluation of hydro system and environment. We suggest to the government to expand the drinking water distribution network in rural areas; to protect water points and advise the population to use simple methods of disinfection of water. This measure has essential in maintaining adequate water quality for the inhabitants of this Ngoumou and environs.

\section{References}

[1] Goshko M. S., Minnigh H. A., Pipes W. O. \& ChristianR. R. (2017). Relationships between standard plate counts andother parameters in water distribution systems. Journal- American Water Works Assoc., 75 (11): 568-571.
[2] Rodier J., Legube B., Marlet N. \& Brunet R. (2009). L'analyse de l'eau. 9e édition, Dunod, Paris, France, 1579p.

[3] Smith H. V. (2007). Cyclospora. Chapter 10. In: Simjee.

[4] S (ed) Foodborne Diseases. Humana Press, Totowa 12: 277-301. Ciçek M., Uçmak F. \& Ozekinci T. (2011). Two diarrheacases caused by Cyclospora cayetanensis Microbiological. Bulletin. 2011; 45: 553-557.

[5] Abdelbaki C. \& Bouklihacène F. (2007). Etude duphénomène de la dégradation des eaux souterraines du groupement urbain de Tlemcen, Revue des Energies Renouvelables, 10 (2): 257-263.

[6] Rodier J., Merlet N. \& Lugube B. (2009). L'analyse del'eau. 9e edition, Dunod, Paris, $1526 \mathrm{p}$.

[7] APHA (1998). Standard method for examination of water and wastewater. American Public Health Association, 20th edition, Washington, DC, 1150p.

[8] Ortega Y. R., Gilman R. H. \& Sterling, C. R. (2009). A new coccidian parasite (Apicomplexa: Eimeriidae) from humans. The Journal of Parasitology, 80 (4): 625-629.

[9] Ajeagah G. A., Njine T., Bilong Bilong C. F., Foto Menbohan S., Wouafo Ndayo M., Nola M., Di Giovanni G. D. \& Huw S. (2010). Seasonal distribution of enteric opportunistic Cryptosporidium spp. (oo) cysts and Giardia spp. Cysts in a tropical water basin, Cameroon. Water, 2: 44-57.

[10] WHO. (2011). Relevéépidémiologiquehebdomadaire, WHO Library Cataloguing-in-Publication; 31: 325-340.

[11] Nisbet M. \& Vernaux J. (1970). Composantes chimiques des eaux courantes. Discussion et proposition des classes en tant que bases d'interprétation des analyses chimiques. Annales de Limnologie; 6 (2): 161-190.

[12] Ortega Y. R. \& Sanchez R. (2010). Update on Cyclospora cayetanensis, a food-borne and Waterborne parasite. ClinicatMicrobiologie Revue.; 23 (1): 218-34.

[13] Boutin C. (1993). L'eau des nappes phréatiques superficielles, une richesse naturelle vitale mais vulnérable. L'exemple des zones rurales du Maroc. Revue des Sciences de l'eau, 6 (3): 357-365.

[14] Lainson R. (2005). The genus Cyclospora (Apicomplexa: Eimeriidae), with a description of Cyclosporaschneiderin. sp. in the snake Aniliusscytalescytale (Aniliidae) from Amazonian Brazil - A review. Memórias do Instituto Oswaldo Cruz 100 (2): 103-110.

[15] Haas C. N., Meyer M. A. \& Paller M. S. (1983). Microbial alterations in water distribution systems and their relationship to physical-chemical characteristics. Journal- AmericanWater Works Assoc., 75: 475-481.

[16] ZébazéTogouet S. H., Tuekam Kayo R. P., Boutin C., Nola M. \&FotoMenbohan S., (2011). Impact de la pression anthropique sur l'eau et la faune aquatique des puits et sources de la région de Yaoundé (Cameroun, Afrique Centrale). Bulletin de la société d'Histoire Naturelle de Toulouse, 147: 27-41.

[17] Snead M. C., Olivieri V. P., Kruse C. W. \&Kawata K. (1980). Benefits of maintaining chlorine residual in water supply systems. U. S. Environmental Protection Agency, Washington, DC. June (EPA-600/2-80-010). 